\title{
Analysis of Expansion Joints for Gas Duct Movement in Corex Process
}

\author{
Kedar M. Kulkarni ${ }^{1}$, Nilesh R. Patil ${ }^{2}$ \\ Assistant Professor, Department of Mechanical Engineering, KJEI's Trinity Academy of Engineering, Pune ${ }^{1,2}$
}

\begin{abstract}
Corex process is one of the modern technologies used for iron making. This process utilizes the hot gases from the melter gasifier. There are huge ducts included into the process. One of their ducts viz. the Reduction gas duct has a slant duct below the reduction shaft which has been displaced from its original position over the years by $57 \mathrm{~mm}$. In this project, the causes of such movement in the duct are to be investigated. There are number of expansion joints used along duct carrying the hot gases which accommodate thermal expansion of the ducts due to temperature changes. The movement of reduction gas duct could be related to the structural vibrations due to the gas flow in the process. Pressure of gas in the process is about $0.3 \mathrm{MPa}$ and temperature is about $8500 \mathrm{C}$. So, as combined effect of pressure and temperature, the duct movement may take place. Hence the problem was taken up for analysis.
\end{abstract}

Keywords: Gimbal, Expansion Joints, Corex Process, Bellows

\section{INTRODUCTION}

Expansion joints are used in the various locations of the ducts carrying the gases at high pressure and temperature. These joints absorb vibrations due to flow of gases and also absorb variations of ducts due to the pressure and thermal expansion by the joints undergoing displacement. So, effect of an expansion joint is to be considered while analysis. The reduction gas duct is modelled by using I-DEAS software. The Analysis is carried out by considering same material for reduction gas duct and by considering expansion joint properties.

\section{LITERATURE REVIEW}

In this literature review the work done in Corex process \& expansion joint work by various researchers is introduced.

1. Englund T., Wall J., et al carried out theoretical modeling, simulations and experimental studies about flexible joints. So, for that purpose Theoretical modeling is to be carried out firstly. After modeling there should be some correlation between theoretical model and experimental investigation.

2. Englund T., Wall J., et al updated the procedure for simulation by using Finite element software. The sum of differences between theoretically and experimentally obtained natural frequencies is chosen as an objective function is to be minimized. All boundary conditions are utilized to obtain mode shapes. These mode shapes from simulation are then correlated with theoretical values.

3. Kedar Kulkarni, Y. P. Reddy et al have done a work The analysis of RGD movement has been carried out in MSCADAMS software. The stiffness is classified into two parts as per the construction of various expansion joints viz. Translational stiffness and Rotational Stiffness.

4. Herran-Gongalez A., De la cruz J.M. [5] focused on modeling and simulation of gas distribution pipeline network. Isothermal, Unidirectional flow is usually assumed while modeling gas flow through duct. They showed that pressure drop is independent on inclination of duct. Gas distribution networks are systems with huge pipes, production storage and distribution centers. This network is constructed to carry out enough gas in desired distances. When gas passes through duct, pressure and energy losses takes place due to friction between gas and inner wall of the ducts. Some losses take place while transfer of heat between gas and environment. When pressure demand is at specific value, the pressure could not reach at specified location. So, pressure drop occurs. When gas pressure increases then certain safety limits could be exceeded. So, to control such situations pressure regulators should be installed at particular locations within defined pressure limits.

5. Li C., Wei Y. et al studied about unwanted deposition of particles on bend decreases the efficiency of equipment. Generally it is observed that the deposition rate expands gradually from top to bottom of inner wall. But increase in velocity of particle decreases deposition of material. Better understanding of particle distribution and deposition is necessary to improve indoor quality. Computational Fluid Dynamics (CFD) is an efficient tool to expose the turbulent phenomena.

6. Lampert K. and Ziebik A. studied about combination of Blast furnace and Corex process. They found out the solution for less use of coke in iron making processes. The blast-furnace process is modified with work in conditions 


\title{
International Advanced Research Journal in Science, Engineering and Technology
}

\author{
Vol. 6, Issue 4, April 2019
}

of increased pressure and high temperature of the blast and with the application of fuels and blast improved with low use of coke. Another way to save coke is the injection of hot reducing gases into the thermal zone. Practically this way is possible because the capacity of a modern blast furnace is usually limited due to slower flow of liquid products in the zone.

The amounts of reducing gases formed in the tuyeres zone of a modern blast furnace confirm to be insufficient for the complete reduction of Ferrous oxides. These restrictions keep away from producing some parts of the reducing gases outside the blast furnace and injecting them into the thermal reserve zone.

\section{METHEDOLOGY}

The process of investigating cause behind movement is followed by analysis of expansion joints. The initial model was developed by using IDEAS software. The flowchart in fig 1 represents a methodology adopted for a current work described.

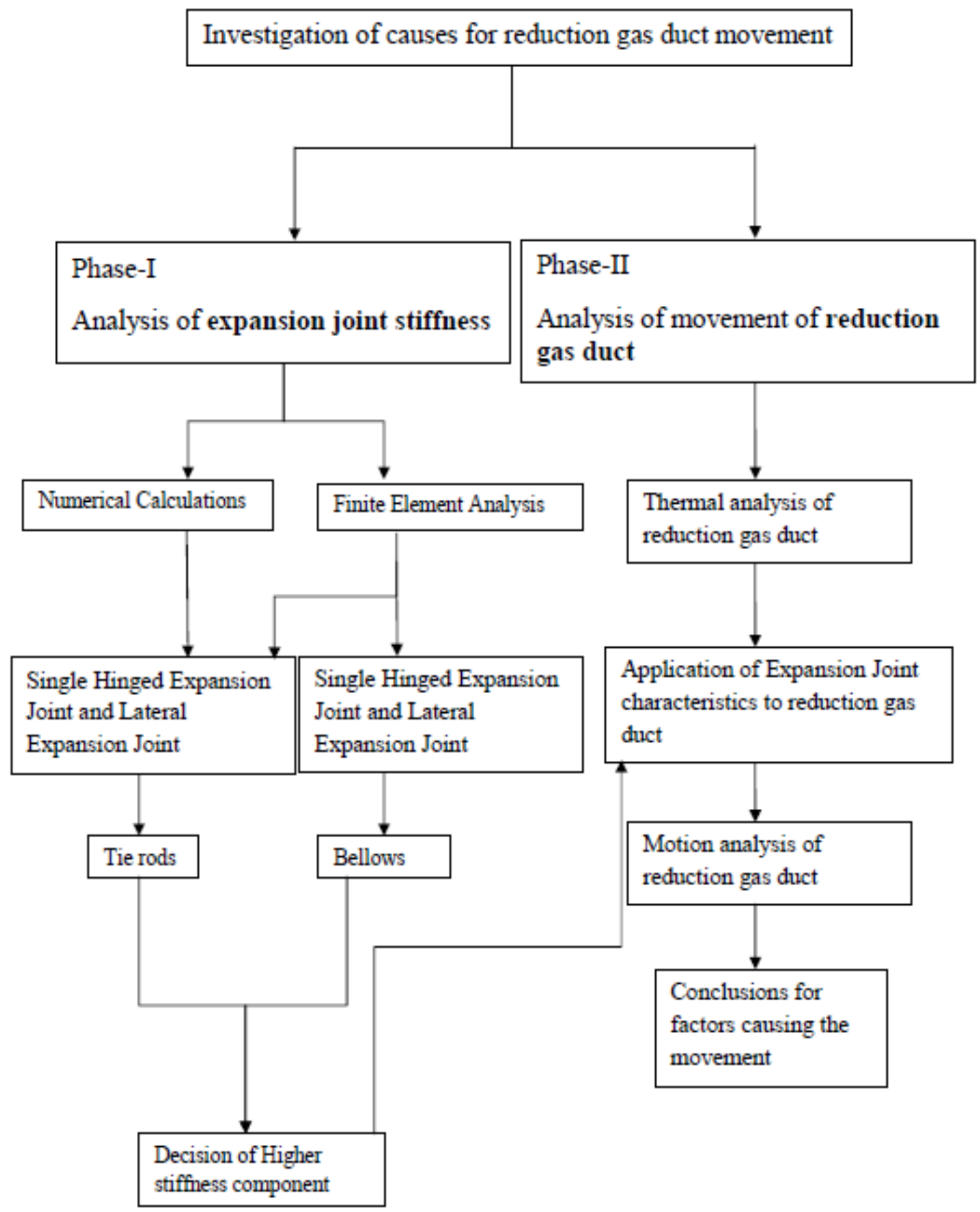

Figure. 1. Methodology of Proposed Design. 


\section{International Advanced Research Journal in Science, Engineering and Technology}

Vol. 6, Issue 4, April 2019

\section{IV. $\quad$ ANALYSIS OF EXPANSION JOINTS}

The Finite Element Analysis applied on an intended model is discussed below.

\subsection{Need of Analysis}

$>$ Bellows are used to absorb dimensional changes such as those caused by pressure variations and initial misalignment in pipe-lines, ducts or vessels and their components. For analyzing the bellow Altair Hyperworks v11 (Radioss solver) software has been used.

$>$ Figure $2 \& 3$ shows meshed model of bellows. Two plies have been used for construction of bellow. Ply thickness of one ply is $1.2 \mathrm{~mm}$. As the thickness is too less, 2-D shell meshing has been used for bellow.

One side of bellows has been fixed with constraints and force of $1 \mathrm{~N}$ has applied on the other side.

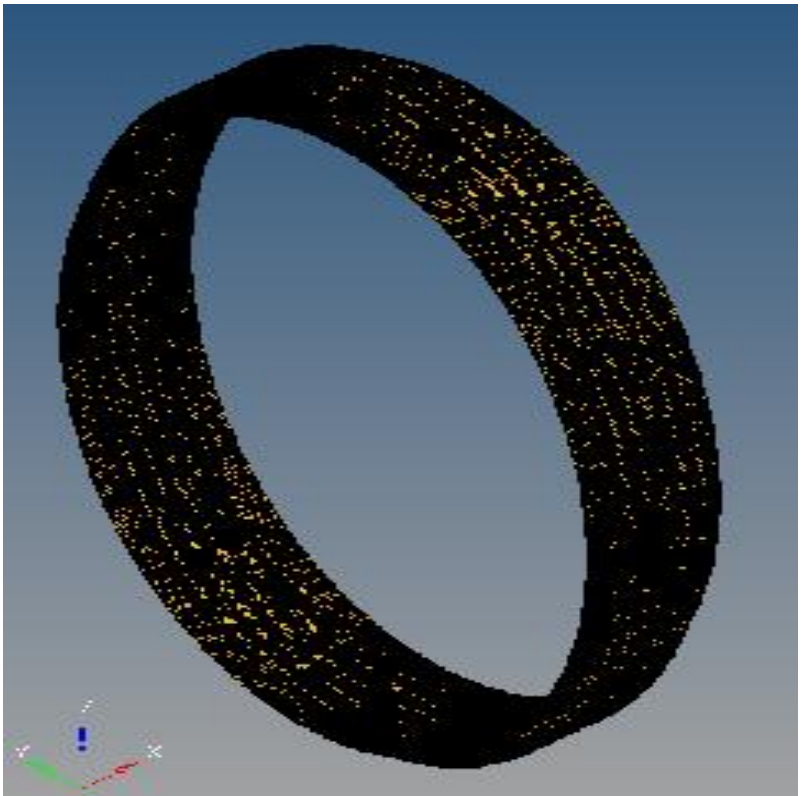

Figure 2. Meshed model of bellows in single hinged expansion joint

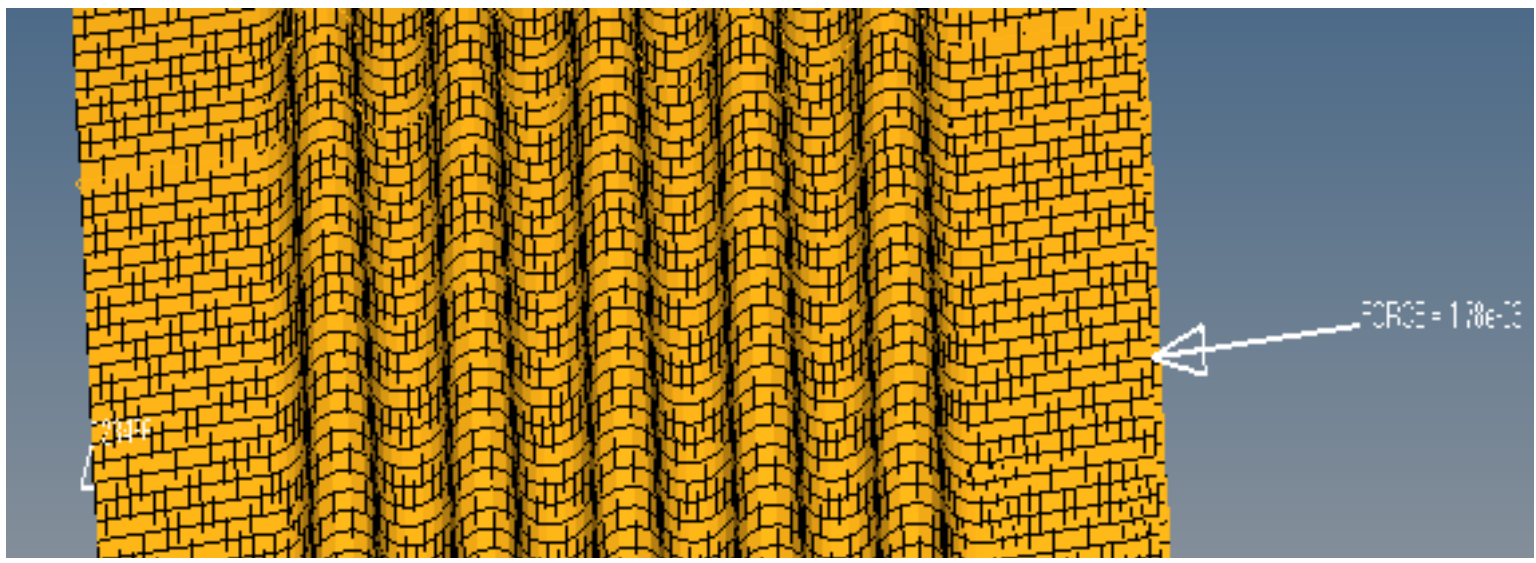

Figure 3.Enlarged View of Meshed model of bellows in single hinged expansion joint

The motion of direction of wheelchair is controlled by steering.

$>$ The device is operated by to and fro motion of steering which help to rotate the wheel, the turning action takes place by tilting the steering forward and backward direction. 


\section{International Advanced Research Journal in Science, Engineering and Technology}

Vol. 6, Issue 4, April 2019

\subsection{Mesh Information}

The model of Single hinged expansion joint is meshed in Hypermesh V11 software. Table no. 1 shows the details of the same.

\begin{tabular}{|c|l|c|}
\hline Sr. No. & \multicolumn{1}{|c|}{ Criteria } & Values \\
\hline 1. & No. of nodes & 218356 \\
\hline 2. & No. of elements & 218057 \\
\hline 3. & Element size & 5 \\
\hline 4. & Mesh type & Mixed \\
\hline 5. & Warpage & $<5$ \\
\hline 6. & Aspect Ratio & $<5$ \\
\hline 7. & Skew & $<45$ \\
\hline 8. & Jacobian & $<0.7$ \\
\hline
\end{tabular}

Table 1. Mesh Information for Single Hinged Expansion Joint

\section{MATERIAL SELECTION \& ANALYSIS}

The material is selected for expansion joint to give input for analysis in software. Expansion Joints Manual(EJMA) is referred for the same.

\subsection{Mechanical Properties of Material}

Material used for duct is Mild Steel. The details given are:

i. Modulus of Elasticity: $2.1 \times 105 \mathrm{MPa}$ (at room temperature)

ii. Density: $7.9 \times 10-9$ tonne $/ \mathrm{mm} 3$

iii. Poissons ratio: 0.3

iv. Thermal conductivity : $26 \mathrm{~W} / \mathrm{m}-\mathrm{K}$

\subsection{Design Specifications}

The design Specifications of duct are enlisted blow:

1.Mass : 61.068 tonnes

2. Pressure : $0.3 \mathrm{MPa}$

3. Temperature of gases inside duct : $8500 \mathrm{C}$

4. Outer surface temperature of steel duct:550C

5. Steel Duct External diameter $: 1820 \mathrm{~mm}$

6. Steel Duct Internal diameter $: 1790 \mathrm{~mm}$

7. Thickness of steel duct: $15 \mathrm{~mm}$

\subsection{Analysis}

Fig. 4 shows the analysis of single hinged expansion joint. The displacement contour is shown in the fig. Bellows has $0.003019 \mathrm{~mm}$ maximum displacement. For calculating the stiffness following formula has been used:

$$
k=\frac{F}{x}
$$

Where, $\mathrm{k}=$ stiffness in $\mathrm{N} / \mathrm{mm}, \mathrm{F}=$ force applied in $\mathrm{N}, \mathrm{x}=$ displacement in $\mathrm{mm}$. For bellows, force applied is $1 \mathrm{~N}$ and displacement of $3.019 \times 10^{-3}$ has obtained. By substituting these values in equation axial stiffness is given by,

$$
\mathrm{k}=331.23 \mathrm{~N} / \mathrm{mm}
$$




\section{International Advanced Research Journal in Science, Engineering and Technology}

Vol. 6, Issue 4, April 2019

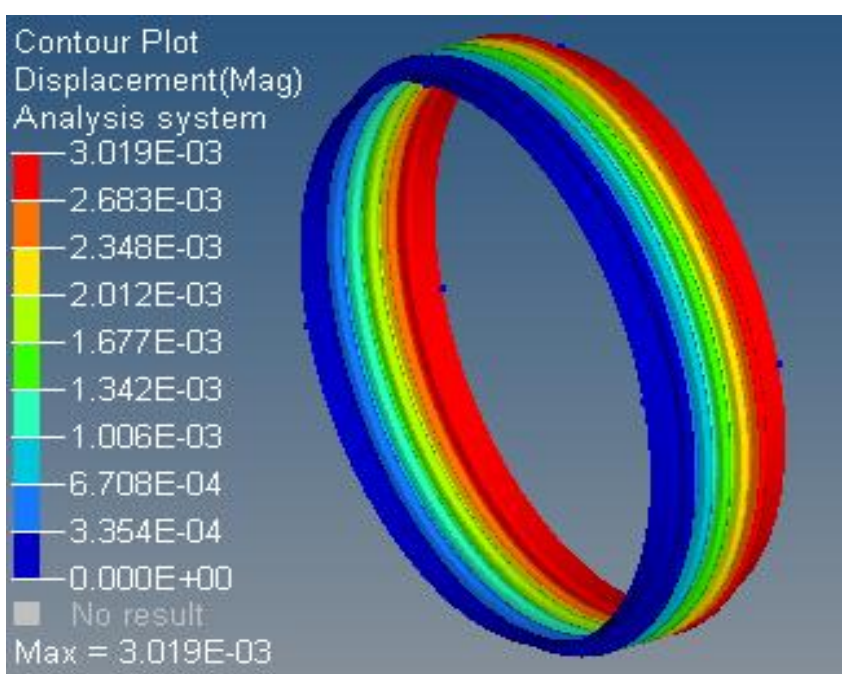

Figure 4.Displacement contour for bellows in single hinged expansion joint

It is proved with the finite element analysis that the bellows absorb some of the pressure thrust by gases. Hence the stiffness of bellows has been considered while analyzing reduction gas duct. This analysis shows that the ducting should be re-designed \& re-manufactured.

\section{CONCLUSION}

The Analysis of Gas duct is carried out for various movements of expansion joints. Only Single Hinged Expansion Joints are explained in the paper. The gas ducts are not moving due to single hinged expansion Joints. There are another expansion joints such as Gimbal Expansion Joints, Lateral Expansion Joints. The analysis of those expansion joints is also needed. The duct might be moving due to pressure fluctuations. These pressure fluctuations might be occurring due to blockages made by dust particles. The Pressure fluctuations should be reduced to reduce no. of blockages.

\section{REFERENCES}

[1]. Englund T., Wall J. , "Automated updating of simplified component models for exhaust system dynamics simulations", International conference on simulation, modelling and optimization,2002, Proceedings of 2nd WSEAS conference, Skiathos Island, Greece.

[2]. Englund T., Wall J., "Significance of non-linearity and component internal vibrations in an exhaust system", International conference on simulation, modelling and optimization,2002,Proceedings of 2nd WSEAS conference,Skiathos Island, Greece.

[3]. Kedar Kulkarni, Y. P. Reddy, Vasantha Ramaswamy," Analysis of Gas Duct Movement in Corex Process", International Journal of Engineering Research \& Technology (IJERT) Vol. 2 Issue 11, November - 2013

[4]. Li C., Wei Y.,"Numerical and experimental study of particle deposition on inner wall of $180^{\circ}$ bend", Powder technology,2013, 237(1), pp.241254.

[5]. Ziebik A., Lampert K., "Comparative analysis of energy requirements of CO2 removal from metallurgical fuel gases”, Energy, 2007, 33(4), pp.521-527. 